\title{
Biodiesel production from Jatropha curcas L. oil with Ca and La mixed oxide catalyst in near supercritical methanol conditions
}

\begin{abstract}
The catalytic transesterification of crude Jatropha curcus oil (JCO) with supercritical methanol $(\mathrm{scMeOH})$, in the presence of calcium lanthanum mixed oxide $(\mathrm{CaLaO})$ heterogeneous base catalyst was carried out using a batch reactor at near critical temperatures and pressures. The performance of synthesized $\mathrm{CaLaO}$ mixed oxide catalysts was examined by characterizing it through instruments such as XRD, BET and $\mathrm{CO}_{2}-\mathrm{TPD}$, revealed that the $\mathrm{Ca} / \mathrm{La}$ atomic ratio strongly affects the phase structure, catalyst basic sites, and thus the catalytic reactivity. The reaction parameters including $\mathrm{Ca} / \mathrm{La}$ atomic molar ratio in the mixed metal oxide catalyst, molar ratio of methanol to oil, catalyst concentration, reaction pressure, temperature and time were varied one at a time and optimized based on the content of fatty acid methyl esters (FAMEs). The highest FAME yield for supercritical methanolysis reached $93 \%$ under the optimum reaction conditions: $240{ }^{\circ} \mathrm{C}, 8.2 \mathrm{MPa}$, a molar ratio of methanol to oil of $21: 1$, and reaction time of $10 \mathrm{~min}$ in the presence of $1 \mathrm{wt} \%$ catalyst. The results demonstrated that the presence of $\mathrm{CaLaO}$ mixed oxide catalyst in the reaction system effectively reduced reaction temperature, time and pressure of supercritical conditions. It required a very low concentration to mitigate the harsh operation conditions $\left(290{ }^{\circ} \mathrm{C}\right.$, $15 \mathrm{MPa}, 60 \mathrm{~min}$ ) of the $\mathrm{scMeOH}$ process. On the other hand, supercritical reaction compensated for low conversion rate of solid catalytic transesterification whereby, it takes one step further by improving the role of catalyst with supercritical conditions to achieve higher yield and shorter processing time. The reusability of $\mathrm{CaLaO}$ mixed oxide catalyst for repeated use was tested, the catalytic activity was $>80 \%$ when the catalyst was employed for fourth time. The study concluded that slight leaching of $\mathrm{Ca}^{2+}(0.52-6.07 \mathrm{ppm})$ and $\mathrm{La}^{3+}$ (0.34-2.33 ppm) occurred during transesterification reaction, however it is below acceptable levels of metals as ASTM D6751 (United State) and in Europe, EN 14214 (Europe) standards. This proved that heterogeneous catalytic supercritical reaction process is more promising than non-catalytic processes and it can be turned to practical use in the near future.
\end{abstract}

Keyword: Calcium lanthanum; Heterogeneous catalyst; Jatropha curcas; Mixed oxide; Supercritical; Transesterification 